University of Nebraska - Lincoln

DigitalCommons@University of Nebraska - Lincoln

Faculty Publications from the Harold W. Manter Laboratory of Parasitology

Parasitology, Harold W. Manter Laboratory of

$12-1997$

\title{
Limited Range of Genetic Variation in Echinococcus multilocularis
}

\author{
Heinz Rinder \\ Department of Infectious Diseases and Tropical Medicine (Germany) \\ Robert L. Rausch \\ University of Washington, rausch@uw.edu \\ Kenichi Takahashi \\ Hokkaido Institute of Public Health \\ Hartmuth Kopp \\ State Department for Investigative Health Services in Southern Bavaria (Germany) \\ Angelika Thomschke \\ Department of Infectious Diseases and Tropical Medicine (Germany)
}

See next page for additional authors

Follow this and additional works at: https://digitalcommons.unl.edu/parasitologyfacpubs

Part of the Parasitology Commons

Rinder, Heinz; Rausch, Robert L.; Takahashi, Kenichi; Kopp, Hartmuth; Thomschke, Angelika; and Löscher, Thomas, "Limited Range of Genetic Variation in Echinococcus multilocularis" (1997). Faculty Publications from the Harold W. Manter Laboratory of Parasitology. 372.

https://digitalcommons.unl.edu/parasitologyfacpubs/372

This Article is brought to you for free and open access by the Parasitology, Harold W. Manter Laboratory of at DigitalCommons@University of Nebraska - Lincoln. It has been accepted for inclusion in Faculty Publications from the Harold W. Manter Laboratory of Parasitology by an authorized administrator of DigitalCommons@University of Nebraska - Lincoln. 


\section{Authors}

Heinz Rinder, Robert L. Rausch, Kenichi Takahashi, Hartmuth Kopp, Angelika Thomschke, and Thomas Löscher 


\title{
LIMITED RANGE OF GENETIC VARIATION IN ECHINOCOCCUS MULTILOCULARIS
}

\author{
Heinz Rinder, Robert L. Rausch*, Kenichi Takahashi†, Hartmuth Koppł, Angelika Thomschke, and Thomas Löscher \\ Department of Infectious Diseases and Tropical Medicine, Leopoldstr. 5, D-80802 Munich, Germany

\begin{abstract}
DNA sequencing of $1.3 \mathrm{~kb}$ of rDNA containing both internal transcribed spacers (ITS1, ITS2) and adjoining rRNA coding regions in each of 11 Echinococcus multilocularis isolates from Germany, Japan, and Alaska resulted in identical nucleotide sequences except for a single polymorphic locus 54 bp upstream of the $3^{\prime}$ end of the $18 \mathrm{~S}$ coding region, separating Eurasian isolates from an Alaskan isolate. The same base substitution was found in each of 2 additional isolates from Alaska. The distribution of the resulting genotypes with regard to their origin is highly significant $(>99.9 \%)$ and corresponds to the traditional subspecies Echinococcus multilocularis multilocularis and Echinococcus multilocularis sibiricensis.
\end{abstract}

The existence of distinct populations, most often referred to as strains or variants, within the species Echinococcus multilocularis has repeatedly been claimed to explain phenotypic and genotypic differences between members of this species. The discrimination of genetically distinct strains of $E$. multilocular$i s$, when correlated with clinical, morphological, biochemical, and immunological data, is expected to be relevant in explaining differences in susceptibility to chemotherapy, infectivity, and differences in the development of this parasite in infected intermediate hosts (Vogel et al., 1991) and to have implications for epidemiological studies and the elucidation of transmission patterns (Bretagne et al., 1996). Phenotypic and biological differences between strains of $E$. multilocularis have been described with respect to morphology (Vogel, 1957), the spectrum of intermediate hosts (Sakui et al., 1984; Pfister and Frank, 1988), the localization of larval foci in the intermediate host (Vogel, 1957), virulence (Gottstein et al., 1987; Rausch et al., 1987; Bresson-Hadni et al., 1994), antigen expression (Gottstein et al., 1991), and the prepatent period in the definite host (Thompson and Eckert, 1983).

In principle, factors affecting the parasites' morphology and biology could be contributed by the host, the parasite, or both. They could be controlled by the environment, or be genetically determined, or both. Investigations on possible host contributions have been few (Kroeze and Tanner, 1987; Gottstein et al., 1994) and divergent for susceptibility to and clinical prognosis of the infection in humans (Scherbakov, 1993; Gottstein and Bettens, 1994). With regard to the parasite, evidence for the existence of distinct strains of $E$. multilocularis has been favorably reviewed (Eckert and Thompson, 1988; Thompson and Lymbery, 1988), and their molecular characterization has been acknowledged as an urgent need (Thompson et al., 1995). Preliminary data are available for the existence of distinct $\mathrm{E}$. $\mathrm{mul}$ tilocularis genotypes by sequencing mitochondrial genes (Bowles et al., 1992; Bowles and McManus, 1993a), Southern hybridization with an anonymous DNA probe (Vogel et al., 1991), random amplification of polymorphic DNA (Scott and McManus, 1994), and analyses of microsatellite polymorphisms (Bretagne et al., 1996). However, due to the small sample sizes (4 or less isolates, except for the latter study) and due to the

Received 24 March 1997; revised 2 July 1997; accepted 2 July 1997.

* Department of Comparative Medicine, University of Washington, Seattle, Washington 98101 .

$\dagger$ Division of Medical Zoology, Hokkaido Institute of Public Health, Japan.

‡ State Department for Investigative Health Services in Southern Bavaria, Oberschleissheim, Germany. choice of the target gene or the employed method to analyze it, their epidemiologic and phylogenetic implications remain unclear.

In an effort to avoid target genes and analysis methods that might represent individual features of different isolates rather than reflect taxonomically relevant phylogenetic relationships, we have chosen the ribosomal RNA gene (rDNA) as the genetic target because during evolution these genes accumulate mutations in a very steady fashion and are, therefore, also called "molecular clocks" (Olsen and Woese, 1993). Their hypervariable spacer regions have repeatedly been useful for taxonomic distinctions at and below the species level, including taeniid cestodes (Gasser and Chilton, 1995). In this report, we have amplified the first and second internal transcribed spacers (ITS1 and ITS2), the enclosed 5.8S, and adjoining portions of the $18 \mathrm{~S}$ and $28 \mathrm{~S}$ rRNA coding sequences from $11 \mathrm{E}$. multilocularis isolates from Germany, Japan, and Alaska in order to find characteristics that might qualify as genetic markers for the description of strains within this species.

\section{MATERIALS AND METHODS}

\section{Echinococcus multilocularis isolates}

All German isolates (nos. 1-9; Table I) were intestinal smears from hunted red foxes (Vulpes vulpes), the Japanese sample (no. 10) was isolated from a trapped vole (Clethrionomys rufocanus bedfordiae), the first Alaskan isolate (no. 11) originated from a human biopsy taken from a resident of St. Lawrence Island in 1982 and had been maintained in voles (Clethrionomys rutilus) and gerbils (Meriones unguiculatus) until the present sample was obtained in 1996. The other 2 samples from Alaska (nos. 12 and 13) originated from voles (Microtus oeconomus and $C$. rutilus, respectively) trapped in May 1996 and were maintained in gerbils ( $M$. unguiculatus) between June and November of the same year. An overview of the geographical origins and hosts is given in Table I.

\section{DNA isolation}

DNA from intestinal smears was isolated by an alkaline lysis method as described previously for stool specimens (Katzwinkel-Wladarsch et al., 1994). DNA from tissue samples was prepared by proteinase K digestion and phenol/chloroform extraction following standard protocols (Sambrook et al., 1989). All DNA was finally purified and concentrated by silica gel adsorption (Geneclean; BIO 101, La Jolla, California) and eluted in $120 \mu \mathrm{l}$ water.

\section{Nested polymerase chain reaction (PCR)}

The rDNA target was amplified by 2 consecutive (nested) PCR reactions. The upstream primer for the first PCR, MSP-3 (GGA ATT CAC ACC GCC CGT C(AG)(CT) TAT), is located in the 3' region of the $18 \mathrm{~S}$ coding sequence and was constructed to match several microsporidian species as described by Katzwinkel-Wladarsch et al. (1996). The downstream primer RIB-3 (CGG GAT CCT TC(AG) CTC GCC $\mathrm{G}(\mathrm{CT}) \mathrm{T}$ ACT) is targeted to a highly conserved section of the $28 \mathrm{~S} 5^{\prime}$ 
TABLE I. Geographical origins and hosts of E. multilocularis isolates examined.

\begin{tabular}{rlll}
\hline & & & $\begin{array}{c}\text { Collec- } \\
\text { tion } \\
\text { No. }\end{array}$ \\
\hline 1 & Bavaria, Germany (south) & Host & year \\
2 & Bavaria, Germany (south) & Fox & 1994 \\
3 & Bavaria, Germany (south) & Fox & 1994 \\
4 & Brandenburg, Germany (east) & Fox & 1995 \\
5 & Brandenburg, Germany (east) & Fox & 1995 \\
6 & North Rhine-Westphalia, Germany (west) & Fox & 1995 \\
7 & North Rhine-Westphalia, Germany (west) & Fox & 1995 \\
8 & Thuringia, Germany (southeast) & Fox & 1994 \\
9 & Lower Saxony, Germany (northwest) & Fox & 1995 \\
10 & Hokkaido, Japan & Vole & 1996 \\
11 & St. Lawrence Island, Alaska, USA & Human & 1982 \\
12 & St. Lawrence Island, Alaska, USA & Vole & 1996 \\
13 & St. Lawrence Island, Alaska, USA & Vole & 1996 \\
\hline
\end{tabular}

region. MSP-3 and RIB-3 were empirically found to be capable of amplifying E. granulosus DNA isolated from hydatic fluid from infected sheep, yielding a $1.7-\mathrm{kb}$ product, and subsequently from isolated $E$. multilocularis adults, which gave a 1.5 -kb product. The inner upstream primer ECH-6 (CCA CTA GTC GCT GAG A(AG)G ACG AC), ending $73 \mathrm{bp}$ before the $3^{\prime}$ end of the $18 \mathrm{~S}$ coding region, and the downstream primer ECH-5 (CGG AAT TCA GCG GGT ACC CAC C), ending 19 bp from the $3^{\prime}$ start of the $28 \mathrm{~S}$ coding region were constructed to match the sequences obtained with MSP-3/RIB-3 from both Echinococcus species but not those of mammalian, plant, bacterial, and fungal rDNA (Dams et al., 1988; Gutell and Fox, 1988) which was expected to contaminate especially the intestinal smears. The PCR reactions were done employing a "hot start" technique in which $38.2 \mu$ l DNA extract (or 2 $\mu \mathrm{l}$ of the first PCR in $37.5 \mu$ l water for the second PCR) was denatured at $96 \mathrm{C}$ for $2 \mathrm{~min}$ after the addition of $1 \mu \mathrm{l}$ each of $50 \mathrm{mM}$ solutions of the primers, $1.8 \mu \mathrm{l}(1.5 \mu \mathrm{l}$ for the second PCR $)$ of $50 \mathrm{mM} \mathrm{MgCl}_{2}, 2$ $\mu l$ ( $1 \mu$ l for the second PCR) of dimethyl sulfoxide (DMSO), and 2 drops of mineral oil. After cooling to $85 \mathrm{C}, 6 \mu \mathrm{l}$ of a freshly prepared mixture of $5 \mu$ l buffer ( $100 \mathrm{mM}$ Tris- $\mathrm{HCl}[\mathrm{pH} 8.3], 500 \mathrm{mM} \mathrm{KCl}), 0.5$ $\mu l$ of dNTP mix ( $25 \mathrm{mM}$ each; United States Biochemical Corporation, Cleveland, Ohio), and $0.5 \mu \mathrm{l}(5 \mathrm{u} / \mu \mathrm{l})$ of $\mathrm{Taq}$ polymerase (Amersham Buchler, Braunschweig, Germany) was added; 40 cycles ( 30 for the second PCR) were performed with denaturation at $92 \mathrm{C}$ for $60 \mathrm{sec}$,

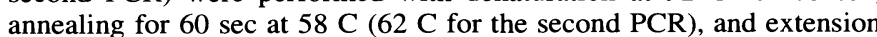
at $72 \mathrm{C}$ for $90 \mathrm{sec}$. Products were visualized in a $1.3 \%$ agarose gel containing $0.2 \mu \mathrm{g} / \mathrm{ml}$ ethidium bromide.

\section{Cloning and sequencing}

The inner primers ECH-6 and ECH-5 included linkers with SpeI and EcoRI sites, respectively, to facilitate the subsequent cloning of the

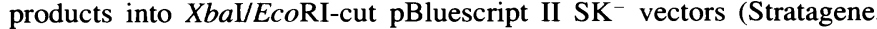
La Jolla, California). Sequencing was performed by dideoxy nucleotide chain termination using a Sequenase II-kit (United States Biochemical Corporation). In addition to the sequencing primers T3 (ATT AAC CCT CAC TAA AG) and KS (CGA GGT CGA CGG TAT CG) located on the vector on both sides of the insert, 8 internal, facing sequencing primers, ECH-7 (GCA AAT CGC AGC AAC GC), ECH-8 (GTG GTT GTT ATC GCT GC), ECH-9 (ACGTCC ACT GAG CAG CC), ECH-10 (GTG TAA TTG GTT TAA GG), ECH-11 (ACG TGA CCA CAG GCA AG), ECH-12 (GTG CAG CCA ACT GTG TG), ECH-13 (TCC ACC ACA GCA TCC AC), and ECH-14 (TGG TGA TGC GGT TGC AG), whose locations are given in Figure 1, were used to obtain sequence information from both DNA strands in order to resolve sequencing compressions and stops. To exclude polymerase errors, the DNA sequences for isolates 1-11 were determined by sequencing 2 clones, each originating from independent PCR amplifications, except for isolate 1 , for which 8 clones amplified in separate PCR reactions were cloned and sequenced once to additionally account for the possibility of intraisolate polymorphisms. All sequences originated from separate PCR amplifications, including isolate 12 and 13 for which only the genotype-discriminating locus $54 \mathrm{bp}$ before the end of the $18 \mathrm{~S}$ coding region was determined by direct sequencing of the PCR products.

\section{RESULTS}

\section{Intraisolate variation}

From 8 independent clones originating from separate PCR amplifications with DNA extracted from isolate no. 1, 1,294 bp of DNA sequence between the inner primers ECH- 6 and ECH-5 were determined (Fig. 1). Taq polymerase errors were detected as individual mutations not found in any other sequenced clone. A total of 10 substitutions was found at different positions in 4 of the sequences. Whereas some of these mutations might be explained by rare intraisolate polymorphisms, the majority are certainly due to polymerase errors because the observed rate of $0.1 \%(10 \mathrm{bp}$ per $8 \times 1,294 \mathrm{bp}=0.00097)$ agrees with the usual rate observed in our laboratory under similar conditions.

\section{rDNA classes}

In several isolates, the repeated generation of a second type of rDNA clones was observed, in some cases originating from the same PCR runs as the first. These products had similar lengths, and their DNA sequences were homologous to, but clearly different from the first rDNA type. Sequencing of 0.23 $\mathrm{kb}$ from the $5^{\prime}$ end (data not shown) revealed an identity of 90\% compared to the rDNA class studied in this report. The identity of this second rDNA class sequence compared to the homologous portion of an E. multilocularis ITS1 sequence reported by Bowles et al. (1995) was $68 \%$. For comparison, the identities between that E. multilocularis and an Echinococcus granulosus (sheep strain) ITS1 sequence reported in the same publication was $86.9 \%$.

\section{Intrapopulation variation}

A total of 9 isolates from 5 different German states (Table I), between 1 and 3 samples each, was characterized. After accounting for polymerase errors by characterizing independent clones from separate PCR amplifications as explained before, identical nucleotide sequences were found for each of the 9 isolates.

\section{Intraspecific polymorphism}

A single polymorphic site was found 54 bp before the $3^{\prime}$ end of the $18 \mathrm{~S}$ coding region. All of the 10 isolates from Germany and Japan displayed an adenine base at this position, whereas all of the 3 isolates from Alaska possessed a guanine there (Fig. 1). For isolates 12 and 13, the identity of this nucleotide was determined by direct sequencing. It was unequivocal at this position and did not require cloning of the PCR products. The rDNA sequence presented in Figure 1 was found to be $78 \%$ identical with the corresponding 992-bp ITS1-containing sequence reported by Bowles et al. (1995), which, however, did not cover the above-described polymorphic locus.

\section{DISCUSSION}

A striking feature of the characterized E. multilocularis isolates is their high degree of genetic conservation within the 


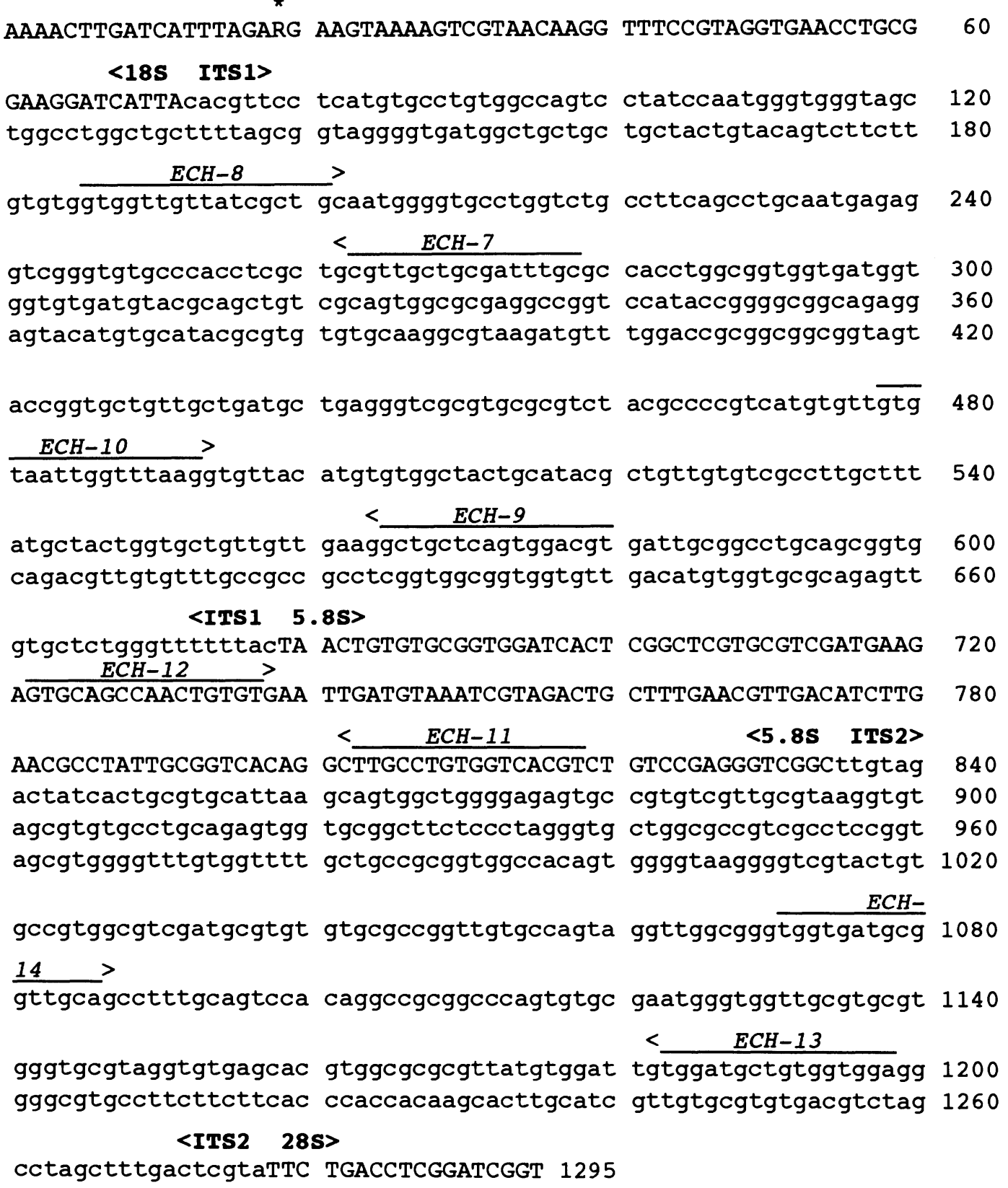

FIGURE 1. Echinococcus multilocularis rDNA sequence between primers ECH-6 and ECH-5. The locations of the coding sequences (capital letters) and spacers (small letters) are approximations inferred from analogies to data on other eukaryotes (Dams et al., 1988; Gutell and Fox, 1988). The locations of the internal sequencing primers is given above the target sequence. *, Polymorphic site; R, adenine (Eurasian isolates) or guanine (Alaskan isolates).

rDNA spacer regions. In contrast, these spacers have been found to be hypervariable in numerous other species of both kingdoms, allowing the differentiation of genetically defined strains within species. A possible explanation could be that $E$. multilocularis is a phylogenetically relatively young species, if speciation is completed at all yet (Bowles et al., 1995).

Second, the location of the single polymorphic site was quite unexpected because it was detected within the $18 \mathrm{~S}$ coding region and not within 1 of the presumably more variable spacer regions of the rDNA gene. The 2 resulting genotypes, nevertheless, are highly significant in discriminating the Alaskan isolates from those of Eurasian origin. The chance of accidentally obtaining this result, i.e., assuming there was no geographic difference in the distribution of these genotypes, is $0.5^{13} \times 2=$ $0.024 \%$ for a $1: 1$ ratio between the genotypes, and $0.77^{10} \times$ $0.23^{3}+0.23^{10} \times 0.77^{3}=0.089 \%$ for the most favorable ratio of 77:23. Because foxes are known to migrate over the sea ice between St. Lawrence Island and northeast Siberia as well as the mainland of Alaska during winter (Fay and Rausch, 1992), it cannot be decided at this point if this genotypic distribution actually represents a restriction of gene flow between Eurasian and Alaskan "strains," or if the allele distribution has not reached equlibrium yet.

These results are congruous with the traditional taxonomic 
classifications of $E$. multilocularis. In their first description, $E$. multilocularis isolates from Alaska have been discriminated from European and Asian isolates and were initially described as a separate species, Echinococcus sibiricensis (Rausch and Schiller, 1954). Later, it was reduced to subspecies status (Vogel, 1957) as 1 of 3 subspecies of E. multilocularis, the others being $E$. $m$. kazakhensis, whose authenticity is, however, disputed as reviewed by Eckert and Thompson (1988), and E. m. multilocularis as the nominate subspecies, whose type locality is southern Germany (reviewed by Eckert and Thompson [1988] and Thompson et al. [1995]). In 1967, even the subspecies status as the lowest valid taxon was given up in favor of the arbitrariness of the term "strain" (Rausch, 1967).

This arbitrariness is in line with the ambiguity of recent genetic characterizations. The first intraspecific genomic differences were described after Southern hybridizations using an anonymous probe called pAL1 whose target gene has not been characterized (Vogel et al., 1991). Several different banding patterns were obtained that could separate some of the 10 isolates studied but did not correlate with their geographical origin. In another pattern analysis technique, the distribution of PCR products of different lengths due to different numbers of pentameric microsatellites upstream of the coding region of the repetitive U1 snRNA gene from 40 different isolates resulted in 3 pattern types (Bretagne et al., 1996). The patterns correlated well, but not completely, with the continent of origin of the samples. Because 1 of the patterns was shared equally between 3 isolates each from Alaska and Hokkaido, Japan, the authors inferred relatedness, whereas more traditional biological studies on host specificities indicate that a population different from that in Alaska is prevalent in all or some areas of Hokkaido (Okamoto et al., 1992). Likewise, seemingly out-dated studies on phenotypic characteristics, such as the sizes of the rostellar hooks, show greater differences between strains from Alaska and Hokkaido than between either of these 2 and European isolates (Rausch and Richards, 1971). Great caution must be exercised when applying microsatellite analysis or other highly discriminating techniques because of the danger of overdiscrimination. Just as a human fingerprint is highly discriminating even between individuals, it offers little information with regard to phylogeny or taxonomy, e.g., when trying to draw conclusions about a person's race. A second confounder that applies to both studies became evident when microsporidia were found in cells from a human liver lesion due to E. multilocularis (Furuya, Sato, et al., 1995). Both the target sequence of the anonymous probe pAL1 as well as the U1 snRNA coding region could be amplified from microsporidial DNA, with corresponding primer pairs previously thought to be genus and species specific, respectively, for E. multilocularis (Furuya, Nagano, and Sato, 1995). Subsequent sequencing of the products revealed almost identical DNA sequences between $E$. multilocularis and the microsporidium Encephalitozoon cuniculi (Nagano et al., 1996).

A third technique generating product patterns, random amplification of polymorphic DNA (RAPD), produced 2 patterns for 2 E. multilocularis isolates (Scott and McManus, 1994). Nevertheless, these findings must be interpreted cautiously, not only because of the danger of overdiscrimination, but also because this random technique often produces random results. They can be difficult to reproduce in other laboratories because this technique is affected by numerous factors, e.g., even by the DNA concentration or the cycling speed (Davin-Regli et al., 1995; Schweder et al., 1995). This situation can be remedied, at least in principle, by DNA sequencing that generates unambiguous as well as quantifiable data at the nucleotide level. This is doubtlessly the reason why 2 reports on sequencing 2 mitochondrial genes, cytochrome c oxidase subunit I (CO1) and NADH subunit I (ND1), in a total of $4 E$. multilocularis isolates (Bowles et al., 1992; Bowles and McManus, 1993a), have received grateful appreciation (Thompson et al., 1995). Two different genotypes were detected although the second genotype was only found in a single isolate and the observed genetic differences did not correspond to geographic divisions (Thompson et al., 1995). Later, CO1 sequences were obtained from 5 Japanese and a second Alaskan isolate and all of them were found to possess the first of the 2 genotypes (Okamoto et al., 1995). The authors of the first 2 reports conclude that CO1 and ND1 data alone are insufficient for phylogenetic analyses and propose the characterization of an rDNA internal transcribed spacer region as a more promising target gene for that purpose (Bowles and McManus, 1993b). However, restriction fragment lengths polymorphism (RFLP) analysis of the ITS 1 of 5 isolates from 3 continents (Bowles and McManus, 1993c), as well as that of the ITS2 of 5 isolates from 2 continents (Gasser and Chilton, 1995) failed to show any differences between the studied E. multilocularis isolates, which is in line with our observations described in this report.

In this context, mention should also be made of the possibility of different "classes" of rDNA genes, even within a single individual (Dover, 1982; Gonzalez et al., 1990; Wesson et al., 1992; Ritland et al., 1993). The existence of different types of rDNA has already been proposed for Echinococcus oligarthrus (Bowles and McManus, 1993c) and E. granulosus (Gasser and Chilton, 1995). We have detected at least 2 rDNA classes in E. multilocularis that could be amplified simultaneously from the same isolates and in the same PCR reactions with the same primer pair. As shown in the results, they were also different from the ITS 1 sequence reported by Bowles et al. (1995), which hence could be interpreted as yet another rDNA class. This observation proves the necessity to clone uncharacterized rDNA products before sequencing rather than sequencing them directly that might result in mixed sequence information.

Further, it is an indispensable though thus far scarcely honored requirement to assess the intraisolate variation that might be amplifiable under the specific conditions and with the particular PCR primers used in a given study. To do this, several PCR reactions should be performed from at least 1 of the isolates and independently generated PCR products should be cloned and sequenced. The same is true for often neglected population genetics aspects in those studies where descriptions of strain differences are sought by characterizing only a single member from each population claimed to thus have been described. The impending pitfall is that differences in rDNA classes could be attributed to represent differences between populations (and subsequently postulated "strains"), whereas they might actually also be found in a single individual if they had been investigated.

As a consequence of the preceding discussion, the lure of rapidly generated and overinterpreted genetic data obtained with more or less appropriate techniques on more or less ap- 
propriate target genes should be realized before principles, if only that of a sufficient sample size to describe a given population, which were self-evident in most "traditional" morphological and biological investigations on taxonomy and phylogeny are put aside as being out-dated. The quick description of a narrow genetic locus of unclear phylogenetic significance in just a few isolates must not be accepted as a convenient shortcut to substitute for the comprehensive and thus more painstaking methods of traditional taxonomy.

In conclusion, the distribution of genotypes described in this report supports the traditional distinction between $E$. m. multilocularis and E. $m$. sibiricensis, be they called subspecies or strains. It presents reason to caution before taxonomic revisions are proposed for E. multilocularis subspecies and strains based on isolated, diverging descriptions of genotypes alone.

\section{ACKNOWLEDGMENTS}

We are indebted to L. Hoffmann and H. Worbes, Bad Langensalza, K. Tackmann, Wusterhausen, M. Takla, Detmold, and M. von Keyserlingk, Hannover, for generously sharing E. $\mathrm{mul}$ tilocularis isolates from different parts of Germany. This work was supported by a grant from the Friedrich-Baur-Stiftung, $\mathrm{Mu}$ nich (no. 10/96).

\section{LITERATURE CITED}

Bowles, J., D. Blair, and D. P. McManus. 1992. Genetic variants within the genus Echinococcus identified by mitochondrial DNA sequencing. Molecular and Biochemical Parasitology 54: 165-174. , - , AND - 1995. A molecular phylogeny of the genus Echinococcus. Parasitology 110: 317-328.

- AND D. P. MCMANus. 1993a. NADH dehydrogenase 1 gene sequences compared for species and strains of the genus Echinococcus. International Journal for Parasitology 23: 969-972.

, AND . 1993b. Molecular variation in Echinococcus. Acta Tropica 53: 291-305.

_, AND —. 1993c. Rapid discrimination of Echinococcus species and strains using a polymerase chain reaction-based RFLP method. Molecular and Biochemical Parasitology 57: 231-240.

Bresson-Hadni, S., J. J. LaPlante, D. Lenys, P. Rohmer, B. GottStein, P. Jacquier, P. Mercet, J. P. Meyer, J. P. Miguet, and D. A. VUITTON. 1994. Seroepidemiologic screening of Echinococcus multilocularis infection in a European area endemic for alveolar echinococcosis. American Journal of Tropical Medicine and Hygiene 51: 837-846.

Bretagne, S., B. Assouline, D. Vidaud, R. Houin, and M. Vidaud. 1996. Echinococcus multilocularis: Microsatellite polymorphism in U1 snRNA genes. Experimental Parasitology 82: 324-328.

Dams, E., L. Hendriks, Y. V. De Peer, J. M. Neefs, G. Smits, I. VanDENBEMPT, AND R. DE WACHTER. 1988. Compilation of small subunit RNA sequences. Nucleic Acids Research 16: r87-r173.

Davin-Regli, A., Y. Abed, R. N. Charrel, C. Bollet, and P. DE Micco. 1995. Variations in DNA concentrations significantly affect the reproducibility of RAPD fingerprint patterns. Research in Microbiology 146: 561-568.

Dover, G. 1982. Molecular drive: A cohesive mode of species evolution. Nature 299: 111-117.

ECKERT, J., AND R. C. A. ThOMPSON. 1988. Echinococcus strains in Europe: A review. Tropical Medicine and Parasitology 39: 1-8.

FAY, F. H., AND R. L. RAUSCH. 1992. Dynamics of the arctic fox population on St. Lawrence Island, Bering Sea. Arctic 45: 393-397.

Furuya, K., H. Nagano, and C. Sato. 1995. Primers designed for amplification of Echinococcus multilocularis DNA amplify the DNA of Encephalitozoon-like spores in the polymerase chain reaction. Journal of Eukaryotic Microbiology 42: 526-528.

, C. Sato, H. Nagano, N. Sato, and J. Uchino. 1995. Encephalitozoon-like organisms in patients with alveolar hydatid disease: Cell culture, ultrastructure, histoimmunochemical localization and seroprevalence. Journal of Eukaryotic Microbiology 42: 518525.

Gasser, R. B., AND N. B. Chilton. 1995. Characterization of taeniid cestode species by PCR-RFLP of ITS2 ribosomal DNA. Acta Tropica 59: 31-40.

Gonzalez, I. L., C. Chambers, J. L. Gorski, D. Stambolian, R. D. SCHMICKEL, AND J. E. SYLVESTER. 1990. Sequence and structure correlation of human ribosomal transcribed spacers. Journal of Molecular Biology 212: 27-32.

GotTSTEIN, B., AND F. BETTENS. 1994. Association between HLA-DR13 and susceptibility to alveolar echinococcosis. Journal of Infectious Diseases 169: 1416-1417.

- C. Lengeler, P. Bachmann, P. Hagemann, P. Kocher, M. BROSSARD, F. WITASSEK, AND J. ECKERT. 1987. Sero-epidemiological survey for alveolar echinococcosis (by Em2-ELISA) of blood donors in an endemic area of Switzerland. Transactions of the Royal Society of Tropical Medicine and Hygiene 81: 960-964.

, B. Mesarina, I. Tanner, R. W. Ammann, J. F. Wilson, J. ECKERT, AND A. LANIER. 1991. Specific cellular and humoral immune responses in patients with different long-term courses of alveolar echinococcosis (infection with Echinococcus multilocularis) American Journal of Tropical Medicine and Hygiene 45: 734-742. , E. WUNDERLIN, AND I. TANNER. 1994. Echinococcus multilocularis: Parasite-specific humoral and cellular immune response subsets in mouse strains susceptible (AKR, C57B1/6J) or "resistant" (C57B 1/10) to secondary alveolar echinococcosis. Clinical and Experimental Immunology 96: 245-252.

Gutell, R. R., AND G. E. Fox. 1988. A compilation of large subunit RNA sequences presented in a structural format. Nucleic Acids Research 16: r175-r269.

KatzWinkel-Wladarsch, S., M. Lieb, W. Heise, T. LösCher, and H. RINDER. 1996. Direct amplification and species determination of microsporidian DNA from stool specimens. Tropical Medicine and International Health 1: 373-378.

- T. LösCHER, AND H. RINDER. 1994. Direct amplification and differentiation of pathogenic and nonpathogenic Entamoeba histolytica DNA from stool specimens. American Journal of Tropical Medicine and Hygiene 51: 115-118.

KROEZE, W. K., AND C. E. TANNER. 1987. Echinococcus multilocularis: Susceptibility and responses to infection in inbred mice. International Journal for Parasitology 17: 873-883.

Nagano, H., C. Satoh, AND K. Furuya. 1996. Nucleotide sequences of DNA fragments of Encephalitozoon cuniculi amplified by polymerase chain reaction with primers regarded as specific for Echinococcus. Journal of Eukaryotic Microbiology 43: 217-221.

OKamoto, M., Y. Bessho, M. KamiYa, T. Kurosawa, and T. HoRiI. 1995. Phylogenetic relationships within Taenia taeniaeformis variants and other taeniid cestodes inferred from the nucleotide sequence of the cytochrome $c$ oxidase subunit I gene. Parasitology Research 81: 451-458.

, O. Fujita, J. AriKawa, T. Kurosawa, Y. Oku, and M. Kamiya. 1992. Natural Echinococcus multilocularis infection in a Norway rat, Rattus norvegicus, in Southern Hokkaido, Japan. International Journal for Parasitology 22: 681-684.

OlsEn, G. J., AND C. R. WOESE. 1993. Ribosomal RNA: A key to phylogeny. FASEB Journal 7: 113-123.

PFISTER, T., AND W. FRANK. 1988. Experimentelle Untersuchungen zur Empfänglichkeit des Schweines für Echinococcus multilocularis. Mitteilungen der Oesterreichischen Gesellschaft fuer Tropenmedizin und Parasitologie 10: 103-114.

RausCH, R. L. 1967. A consideration of infraspecific categories in the genus Echinococcus Rudolphi, 1801 (Cestoda: Taeniidae). Journal of Parasitology 53: 484-491.

- AND S. H. RICHARDS. 1971. Observations on parasite-host relationships of Echinococcus multilocularis Leuckart, 1863, in North Dakota. Canadian Journal of Zoology 49: 1317-1330.

, AND E. L. SCHILlER. 1954. Studies on the helminth fauna of Alaska. XXIV. Echinococcus sibiricensis n. sp., from St. Lawrence Island. Journal of Parasitology 40: 659-662.

-, J. F. Wilson, P. M. SChantZ, and B. J. McMahon. 1987. Spontaneous death of Echinococcus multilocularis: Cases diagnosed serologically (by $\mathrm{EM}_{2}$ ELISA) and clinical significance. American Journal of Tropical Medicine and Hygiene 36: 576-585. 
Ritland, C. E., K. Ritland, and N. A. Straus. 1993. Variation in the ribosomal internal transcribed spacers (ITS1 and ITS2) among eight taxa of the Mimulus guttatus species complex. Molecular Biology and Evolution 10: 1273-1288.

Sakui, M., M. Ishige, S. I. Fukumoto, A. Ueda, and M. Ohbayashi. 1984. Spontaneous Echinococcus multilocularis infection in swine in north-eastern Hokkaido, Japan. Japanese Journal of Parasitology 33: $291-296$.

Sambrook, J., E. F. Fritsch, and T. Maniatis. 1989. Molecular cloning: A laboratory manual, 2nd ed. Cold Spring Harbor Press, Cold Spring Harbor, New York, New York, p. 9.14-9.19.

ScherbaKov, A. M. 1993. Human echinococci: Role of histocompatibility antigens in the realization of invasions and specific features of their course. Meditsinskaya Parazitologiya i Parazitarnye Bolezni Moskow 1993: 13-18.

SChweder, M. E., R. G. Shatters, S. H. West, ANd R. L. Smith. 1995. Effect of transition interval between melting and annealing temperatures on RAPD analyses. BioTechniques 19: 38-42.

SCOTT, J. C., AND D. P. MCMANUS. 1994. The random amplification of polymorphic DNA can discriminate species and strains of Echinococcus. Tropical Medicine and Parasitology 45: 1-4.

ThOMPSON, R. C. A., AND J. ECKERT. 1983. Observations on Echinococcus multilocularis in the definitive host. Zeitschrift fuer Parasitenkunde 69: 335-345.

, AND A. J. LYMBERY. 1988. The nature, extent and significance of variation within the genus Echinococcus. Advances in Parasitology 27: 209-258.

, AND C. C. Constantine. 1995. Variation in Echinococcus: Towards a taxonomic revision of the genus. Advances in Parasitology 35: 145-176.

Vogel, H. 1957. Über den Echinococcus multilocularis Süddeutschlands. Zeitschrift fuer Tropenmedizin und Parasitologie 8: 404454.

Vogel, M., N. MÜller, B. Gottstein, K. Flury, J. Eckert, and T. SEEBECK. 1991. Echinococcus multilocularis: Characterization of a DNA probe. Acta Tropica 48: 109-116.

Wesson, D. M., C. H. Porter, AND F. H. Collins. 1992. Sequence and secondary structure comparisons of ITS rDNA in mosquitoes (Diptera: Culicidae). Molecular Phylogenetics and Evolution 1: 253 269. 